\title{
Mucinous breast carcinoma: Report of four cases and review of the literature
}

\author{
Hiyam Al Haddad ${ }^{*}$, Awadia Awadallah ${ }^{2}$ and Maha Abdel Hadi ${ }^{3}$ \\ ${ }^{1}$ Department of surgery, Consultant Breast surgery, King Fahd Hospital of the University, Imam Abdulrahman Al Faisal University, Dammam, Kingdom of Saudi Arabia \\ ${ }^{2}$ Department of Pathology, Consultant Pathology, King Fahd Hospital of the University, Imam Abdulrahman Al Faisal University, Dammam, Kingdom of Saudi Arabia \\ ${ }^{3}$ Department of Surgery, Consultant Breast surgery, King Fahd Hospital of the University, Imam Abdulrahman Al Faisal University, Dammam, Kingdom of Saudi Arabia
}

\begin{abstract}
Aim: With the increased incidence of breast cancer the accuracy of the diagnosis has risen from the basic typing of disease to many emerging subtypes. The aim of this review is to identify the rare mucinous breast carcinoma and their challenging presentations and management.

Materials and methods: This review was undertaken at King Fahd hospital of the university, Alkhobar, Eastern province of Saudi Arabia between September 2016-Sepetember 2017 All patients diagnosed with breast cancer were reviewed. Demographic data, breast imaging, tissue diagnosis and metastatic workup was performed for all patients.

Results: The total number of patients diagnosed with breast cancer were 92 out of which 4 (4.3\%) patient were diagnosed with pure mucinous breast carcinoma (PMBC), while 1 (1\%) showed mixed type. Age ranged from 34-70 years with the Median age 50 years. Imaging was challenging as in 2 (50\%) of patients the mammogram and ultrasound reported the lesions as BIRADs 4 suggesting low probability of malignancy. Metastatic workup performed in all patients was reported as negative. Axillary node sampling was also reported as negative.

Conclusion: PMBC is an interesting entity with challenging diagnostic imaging. Despite its good prognosis especial emphasis should be exerted in diagnosis. MRI may be an efficient diagnostic tool in middle age and elderly patients who present with newly diagnosed BIRAD 4 masses.
\end{abstract}

\section{Introduction}

Breast cancer is the most common cancer among females worldwide. Invasive ductal carcinoma is the commonest reported variant. Mucinous carcinoma is a relatively rare histological subtype of breast cancer. It accounts to $1-7 \%$ of all invasive breast cancers $[1,2]$. It is characterized by the massive production of extra cellular mucin. The two known subtypes, the pure and mixed are labelled based upon the quantification of cellularity [3]. The pure type consists exclusively of tumor tissue with extracellular mucin production in over of $90 \%$ of the tumor, while the mixed form contains abundant an infiltrating ductal epithelial component without mucin [4].

Pure mucinous breast cancer (PMBC) is characterized by a lower incidence of nodal involvement, favorable histological grade, and higher estrogen receptor (ER) and progesterone receptor (PR) expression [5]. In fact, $\mathrm{PMBC}$ patients generally have a more favorable prognosis compared to invasive ductal carcinoma patients reflected by low recurrence rate. We report 4 cases with pure mucinous breast carcinoma.

\section{Case 1}

60 years old Jordanian female, previously treated for metastatic colorectal cancer on 2008, presented on 2016 with left breast mass of six months duration. Patient was multiparous, with negative systemic symptoms and negative family history.

\section{Case 2}

70 years old Saudi widow with multiple comorbidities presented with a left breast mass discovered on screening mammogram. Patient was multiparous and gave negative family history of breast cancer.

\section{Case 3}

37 years old Saudi female, referred with post excisional biopsy of right breast mass that occurred 5 months prior to her presentation. Patient was multiparous, with negative systemic symptoms and negative family history.

\section{Case 4}

56 years old Indian multiparous female discovered left breast mass on screening mammogram. Patient gave negative systemic symptoms and negative family history.

All patients underwent the standard clinical evaluation, breast imaging, tissue diagnostic biopsies and systemic metastatic workup.

Correspondence to: Hiyam Al Haddad, Consultant Breast surgeon, King Fahd hospital of the University, P.O. Box 40206Al-Khobar 31952, Kingdom of Saudi Arabia, E-mail: dr_hiyam@yahoo.com

Key words: mucinous, breast, cancer

Received: December 03, 2017; Accepted: December 18, 2017; Published: December 22, 2017 


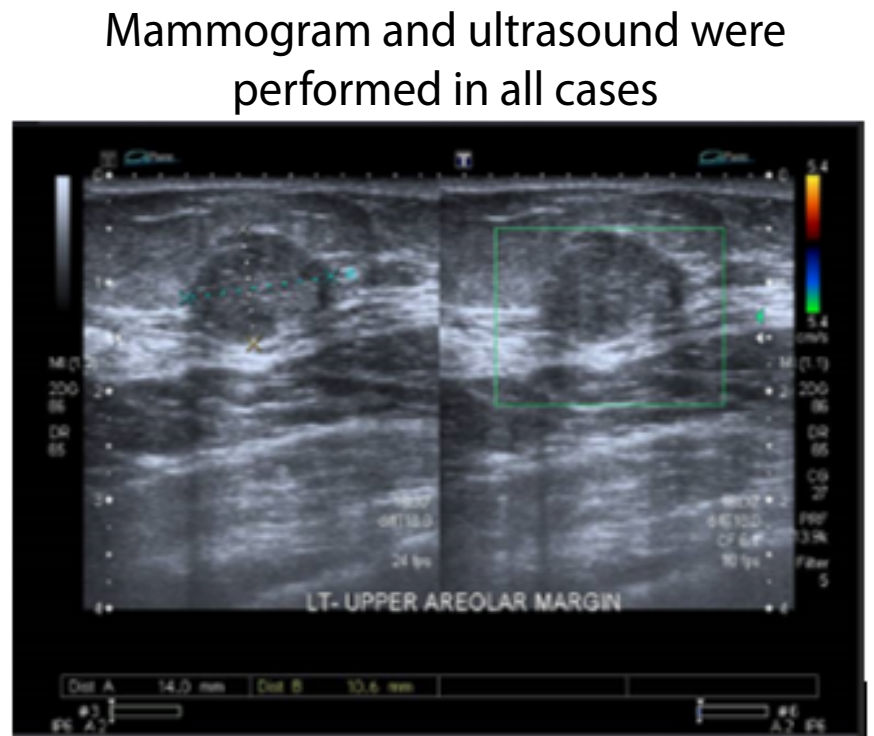

Figure 1. US: A non-vascular heterogeneous mass, slightly hypoechoic with micro lobulated borders at upper areolar margin that measures 15.10.15 mm BIRADS 4A.
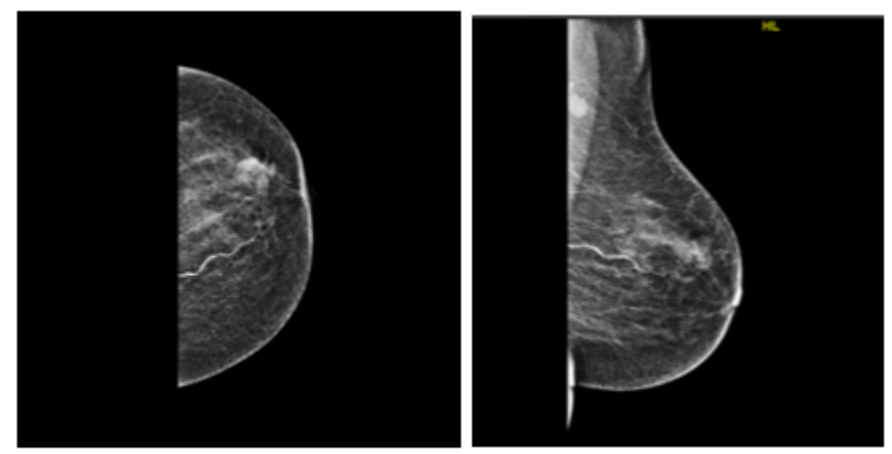

Figure 2. MAM. left breast an irregular mass seen at upper anterior breast associated with ipsilateral suspicious lymph node, measures 20x17x17 mm, BIRADS 4C.

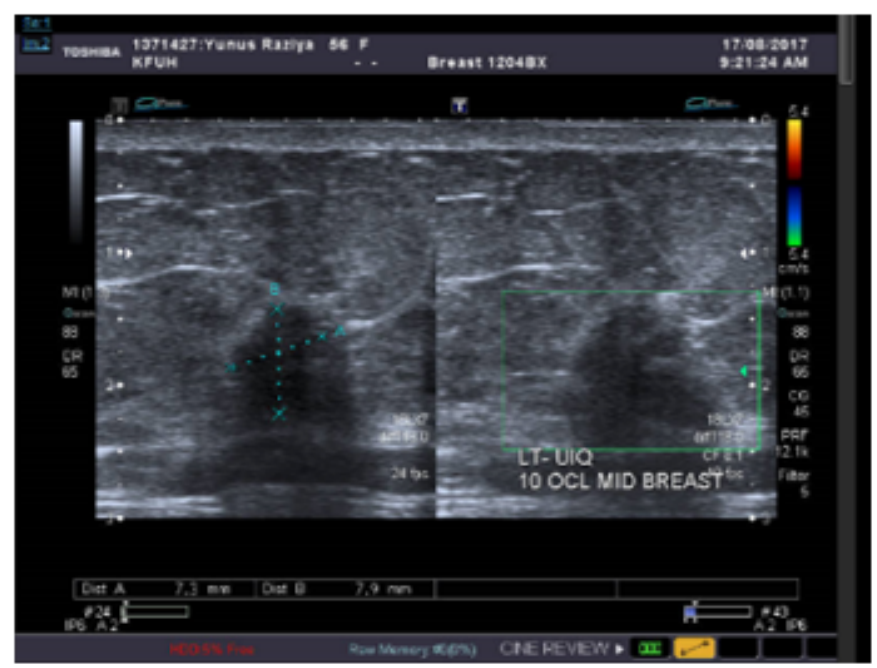

Figure 3. US: Left breast an irregular heterogeneous mass located at upper areolar margin, approximately $14 \times 19$

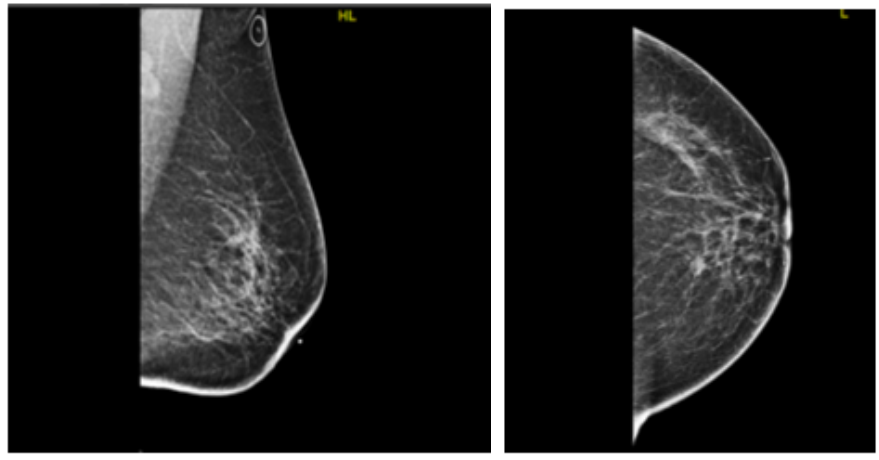

Figure 4. MAM. a small $1 \mathrm{~cm}$ irregular micro lobulated \& speculated mass at right upper inner with benign looking axillary nodes. BIRADS 5.

\section{Discussion}

Mucinous breast carcinoma is a rare condition with challenging imaging diagnosis. In our institution the number of cases diagnosed with PMBC accounted to $4 \%$ of all breast cancer cases. It is a special type of breast cancer, characterized by large production of extracellular mucin. This can either be in the pure form or mixed with ductal epithelial cells [6]. The distinction between these subtypes is based upon the quantification of cellularity. The mucoid component varies between $30 \%-90 \%$ of the tumor component.

The well circumscribed margins and lack of micro-calcifications on basic breast imaging have contributed to the repeatedly reports of such lesions as benign [7].

The magnetic resonance (MRI) features of PMBC is able to differentiate such lesions from benign and other malignant lesions by the distinct feature of mucinous carcinoma that displays a markedly high apparent diffusion coefficient [8].

In this review $50 \%$ of the patient's imaging was reported as low probability of malignancy. The non-alarming radiological appearance of these cases has contributed to some element of delay.

An explicit percentage necessary to diagnose mucinous carcinoma is currently not clearly settled. Most pathologists agree that a diagnosis of pure mucinous breast carcinoma should be reserved for tumors with at least $90 \%$ mucinous component [3]. The pure type consists almost exclusively of tumor tissue with extracellular mucin production, while the mixed subtype also contains an invasive ductal epithelial component without mucin. Pure mucinous breast carcinoma is an uncommon histologic type of mammary tumor, representing $2 \%$ of all breast malignant neoplasms [2]. It has a better prognosis than invasive breast carcinoma of no special type [3,4].

Biopsy is confirmatory in all cases. Mucinous breast carcinomas may also be associated with lobular or ductal neoplasia and some may present with neuroendocrine differentiation [9]. In our series one case (1\%) with mixed mucinous component was encountered in the final pathology.

The slow nature of the disease may contribute to the rarity of the axillary metastases. It is reported in $12-14 \%$ in most series studies $[5,10,11]$. 


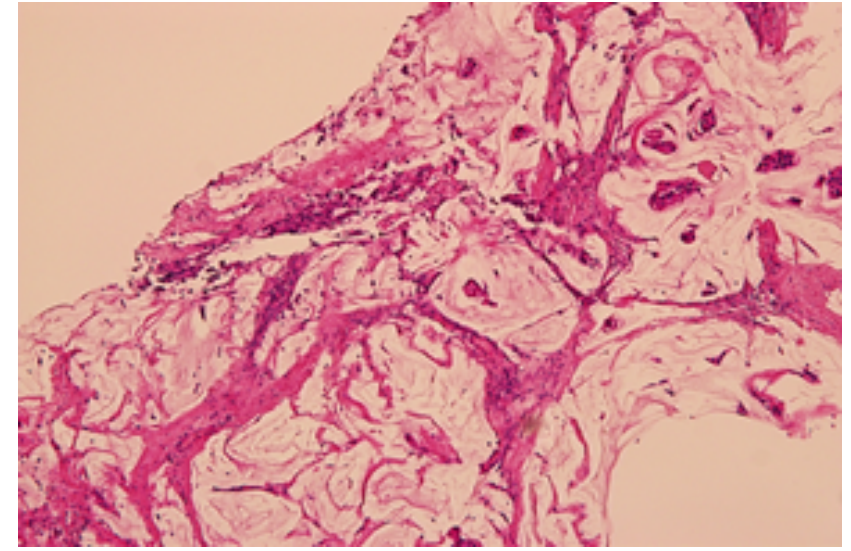

Figure 1. H\&E stain section show Small Island of tumor cells within abundant pool of mucin.

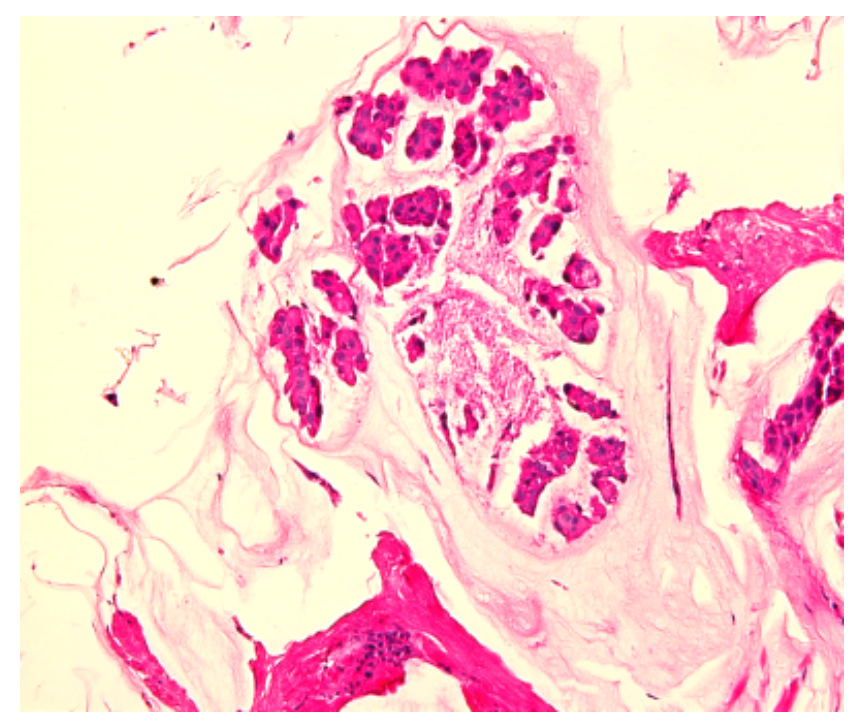

Figure 2. H\&E stain section show small cluster of tumor cells with round to oval nuclei with extracellular mucin.

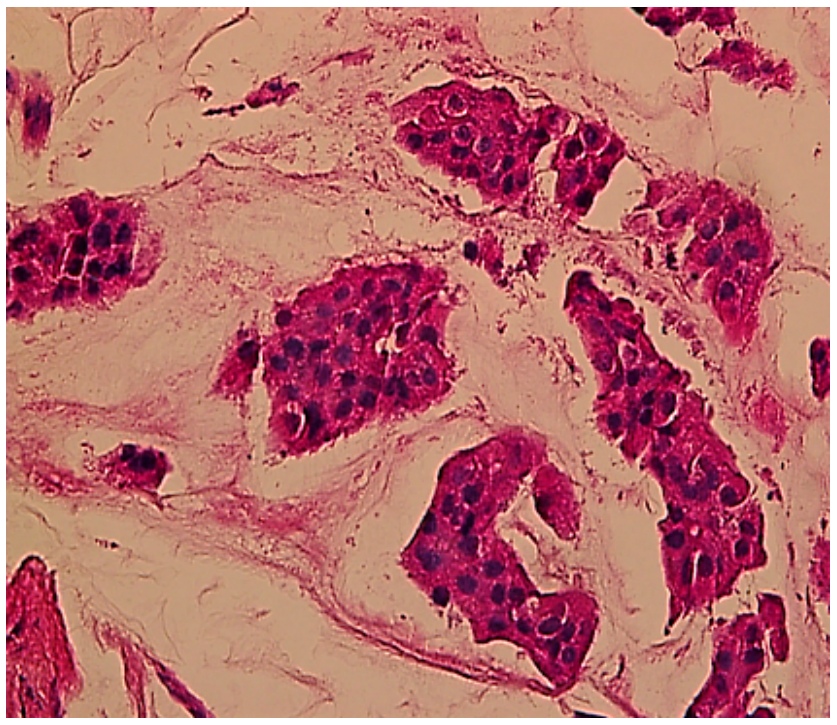

Figure 3. H\&E 40x Show Island of tumor cells with mildly pleomorphic round to oval nuclei with extra-cellular mucin.
Some authors suggest that axillary lymph node staging in these patients might not be necessary since PMBC appears unlikely to metastasize. The presence of lymph node metastases strongly indicates the presence of a mixed mucinous carcinoma [12].

Surgical option remains the same as other breast cancers. Confirmatory reports have suggested that patients with PMBC, except for those cases involving invasion of the local skin, are suitable candidates for breast-conserving therapy, probably even in the presence of large tumors up to $5 \mathrm{~cm}$ in diameter [13].

A recent analysis recommended axillary staging by sentinel lymph node biopsy, and administration of adjuvant radiotherapy and endocrine therapy after breast conserving surgery for mucinous carcinoma [14]. Tumor size in the staging system may not be a significant factor because mucin comprises the majority of the tumor volume [15].

The primary protocol of treatment in patients suffering from mucinous breast carcinoma does not differ from the typical breast cancer surgical options except with the axillary management. Radiotherapy, chemotherapy, endocrine therapy remain options of treatment.

Adjuvant endocrine therapy is indicated for hormone responsive tumors [16]. Nearly all mucinous carcinomas are estrogen- and/or progesterone-receptor positive, which means that hormonal therapy, is likely to be an effective treatment [17]. This report is backed by the positive receptor results obtained from our patients.

Many reports stated that adjuvant chemotherapy could potentially be omitted in cases with favorable risk factors.

In conclusion, it is imperative to clearly distinguish between the pure and mixed mucinous carcinomas as they differ in management planning in addition to the better prognosis the pure subtype carries.

\section{References}

1. Komaki K, Sakamoto G, Sugano H, Morimoto T, Monden Y (1988) Mucinous carcinoma of the breast in Japan. A prognostic analysis based on morphologic features Cancer 61: 989-996. [Crossref]

2. Louwman MW, Vriezen M, van Beek MW, Nolthenius-Puylaert MC, van der Sangen MJ, et al. (2007) Uncommon breast tumors in perspective: incidence, treatment and survival in The Netherlands. Int J Cancer 121:127-135. [Crossref]

3. Hanagiri T, Ono K, Baba T, So T, Yamasaki M, et al. (2010) Clinicopathologic characteristics of mucinous carcinoma of the breast. Int Surg 95: 126-129.

4. Di Saverio S, Gutierrez J, Avisar E (2008) A retrospective review with long term follow up of 11,400 cases of pure mucinous breast carcinoma. Breast Cancer Res Treat 111: 541-547. [Crossref]

5. Diab SG, Clark GM, Osborne CK, Libby A, Allred DC, et al. (1999) Tumor characteristics and clinical outcome of tubular and mucinous breast carcinomas $J$ Clin Oncol 17: 1442-1448. [Crossref]

6. Bae SY, Choi MY, Cho DH, Lee JE, Nam SJ, et al. (2011) Mucinous carcinoma of the breast in comparison with invasive ductal carcinoma: clinicopathologic characteristics and prognosis. J Breast Cancer 14: 308-313. [Crossref]

7. Chopra S, Evans AJ, Pinder SE, Yeoman LJ, Ellis IO, et al. (1996) Pure mucinous breas cancer-mammographic and ultrasound findings. Clin Radiol 51: 421-424. [Crossref]

8. Zhang L, Jia N, Han L, Yang L, Xu W, et al. (2015) Comparative analysis of imaging and pathology features of mucinous carcinoma of the breast. Clin Breast Cancer15: 147-154. [Crossref]

9. Park S, Koo J, Kim JH, Yang WI, Park BW, (2010) et al. Clinicopathologica characteristics of mucinous carcinoma of the breast in Korea: comparison with invasive ductal carcinoma-not otherwise specified. J Korean Med Sci 25: 361-368. [Crossref]

10. Lesser ML, Rosen PP, Senie RT, Duthie K, Menendez-Botet C, et al. (1981) Estrogen and progesterone receptors in breast carcinoma: correlations with epidemiology and pathology. Cancer 48: 299-309. [Crossref] 
11. Vo T, Xing Y, Meric-Bernstam F, Mirza N, Vlastos G, et al. (2007) Long-term outcomes in patients with mucinous, medullary, tubular, and invasive ductual carcinoma after lumpectomy. Am J Surg 194: 527-531. [Crossref]

12. Paramo JC, Wilson C, Velarde D, Giraldo J, Poppiti RJ, et al. (2002) Pure mucinous carcinoma of the breast: is axillary staging necessary? Ann Surg Oncol 9:161-164. [Crossref]

13. Anan K, Mitsuyama S, Tamae K, Nishihara K, Iwashita V, et al. (2001) Pathological features of mucinous carcinoma of the breast are favorable for breast-conserving therapy. Eur J Surg Oncol 27: 459-446.
14. Barkley CR, Ligibel JA, Wong JS, Lipsitz S, Smith BL, et al. (2008) Mucinous breast carcinoma: a large contemporary series. Am J Surg 196: 549-551. [Crossref]

15. Capella C, Eusebi V, Mann B, Azzopardi JG (1980) Endocrine differentiation in mucoid carcinoma of the breast. Histopathology 4: 613-630. [Crossref]

16. Ranade A, Batra R, Sandhu G, Chitale RA, Balderacchi J (2010) Clinicopathological evaluation of 100 cases of mucinous carcinoma of breast with emphasis on axillary staging and special reference to a micropapillary pattern. J Clin Pathol 63:1043-1047. [Crossref]

17. Nakagawa T, Sato K, Moriwaki M, Wada R, Arakawa A, et al. (2012) Successful endocrine therapy for locally advanced mucinous carcinoma of the breast. Breast $J 18$ 632-633. [Crossref]

Copyright: $₫ 2017$ Haddad HA. This is an open-access article distributed under the terms of the Creative Commons Attribution License, which permits unrestricted use, distribution, and reproduction in any medium, provided the original author and source are credited. 